\title{
A RESEARCH ON ACUTE PANCREATITIS IN THANJAVUR MEDICAL COLLEGE
}

\author{
S. Jagathesan 1 , M. Elangovan ${ }^{2}$, A. Muthuvinayagam ${ }^{3}$, R. Raghupathi ${ }^{4}$ \\ ${ }^{1}$ Senior Assistant Professor, Department of General Surgery, Thanjavur Medical College. \\ ${ }^{2}$ Professor, Department of General Surgery, Thanjavur Medical College. \\ ${ }^{3}$ Assistant Professor, Department of General Surgery, Thanjavur Medical College. \\ ${ }^{4}$ Postgraduate Student, Department of General Surgery, Thanjavur Medical College.
}

\section{ABSTRACT}

\section{BACKGROUND}

Aims and Objectives- The research study was designed to recognise the clinical picture of acute pancreatitis in the Indian patients to evaluate common aetiologies, role of investigations and outcome of early conservative management.

\section{MATERIALS AND METHODS}

This study was conducted in 54 patients of acute pancreatitis who were admitted in Thanjavur Medical College during the period of September 15 to December 16. This study was defined to evaluate conservative management of mild-to-moderate pancreatitis; 54 cases of acute pancreatitis were admitted and investigated and treated. Observations were made with regards to common presentation, sex distribution, common aetiology and common blood parameters, especially sr. lipase and sr. amylase.

\section{RESULTS}

The highest incidence of acute pancreatitis was found in the age group of 25 to 35 years followed by the age group of 35 to 55 years. Acute pancreatitis was found more commonly in males compared to females. This may be due to effect of alcohol addiction in males. In acute pancreatitis, serum lipase level may be elevated more consistently and for longer half-life than serum amylase.

\section{CONCLUSION}

The clinical pattern of acute pancreatitis varies in different patients. Though gall stones induced acute pancreatitis is common in western countries, Alcohol is the main aetiological factor in our study. It is recommended that all patients with pancreatitis should undergo ultrasound within 24 hours of admission, as it confirms gallstones and severe pancreatitis. We have started oral feeding in all cases of mild-to-moderate pancreatitis.

\section{KEYWORDS}

Acute Pancreatitis (AP), Alcohol, Gallstones, Abdominal Pain, Serum Amylase and Octreotide.

HOW TO CITE THIS ARTICLE: Jagathesan S, Elangovan M, Muthuvinayagam A, et al. A research on acute pancreatitis in Thanjavur Medical College. J. Evolution Med. Dent. Sci. 2017;6(30):2446-2450, DOI: 10.14260/Jemds/2017/528

\begin{abstract}
BACKGROUND
Acute pancreatitis is a common cause of acute abdominal pain requiring hospital admission. The attack is mild in about $80 \%$ of patients who will show marked improvement within 48 hours. In some $20 \%$ of patients, however, it is often severe with high morbidity and mortality.(1) The first 12 hours are extremely important to provide appropriate management, which will decrease morbidity and mortality. Nearly, $80 \%$ of cases of AP worldwide are caused by gallstone obstruction and high alcohol intake.(2,3) It is necessary to identify the aetiology to institute definitive management and prevent further incidence. There appears to be an increase in the incidence of acute pancreatitis. This rise in incidence has been attributed to increased alcohol consumption, but may well reflect improved diagnostic capability during this period. No seasonal or weekly pattern of acute pancreatitis has been observed. Men are affected much more than women.
\end{abstract}

Financial or Other, Competing Interest: None.

Submission 06-03-2017, Peer Review 02-04-2017,

Acceptance 07-04-2017, Published 13-04-2017.

Corresponding Author:

Dr. S. Jagathesan,

Senior Assistant Professor,

Department of General Surgery,

Thanjavur Medical College, Thanjavur.

E-mail:drjagadeshs@gmail.com

DOI: $10.14260 /$ jemds $/ 2017 / 528$

(c) $(\mathrm{i})($

\section{MATERIALS AND METHODS}

This study was conducted in 54 patients of acute pancreatitis admitted in Thanjavur Medical College; 54 cases of acute pancreatitis were admitted and investigated and treated. Observations were made with regards to common presentation, sex distribution, common aetiology and common blood parameters. All patients were assessed, managed either conservatively or surgically. The findings were recorded in a master chart. It was designed to record the history, chief complaints, past history, family history, personal history, diet history, alcohol consumption, obstetric and menstrual history (in case of female patient), physical examination, local examination, operative history, investigations and management. The clinical presentation associated medical conditions, laboratory and radiological investigations, severity, management and outcome were studied. The attack was categorised as severity based on clinically and radiologically and those with serious comorbidity were admitted to ICU and monitored. All patients had full blood count and blood chemistry including serum amylase and serum lipase; CRP estimation was done and biliary pancreatitis was diagnosed when biliary stones were demonstrated by ultrasonogram, which was performed within 24 hours of admission and OGD Scopy was also done in all patients. CECT scan was performed on all patients. All patients were treated conservatively initially with 
intravenous fluids and nil orally up to 24 hours of admission. Patients who had bowel sounds without any distension started enteral feeding after 24 hours of admission. No patients were given octreotide injection.(4)

\section{RESULTS}

The highest incidence of acute pancreatitis was found in the age group of 25 to 35 years followed by the age group of 35 to 55 years. Acute pancreatitis was found more commonly in males compared to females. This may be due to effect of alcohol addiction in males. In acute pancreatitis, serum lipase level may be elevated more consistently and for longer halflife than serum amylase.

\section{DISCUSSION}

In the study of 54 cases of acute pancreatitis following observations are made.

\section{Age Group}

Most commonly affected age group in this study is 25 to 35 years and mean age is 29 years. As compared to females, male patients are more affected by acute pancreatitis in our study. Presenting Symptoms: From the table below it is evident that abdominal pain is the commonest presenting symptom, present in almost all the patients; of these $50 \%$ of patients presented with typical epigastric pain that radiate to the back.

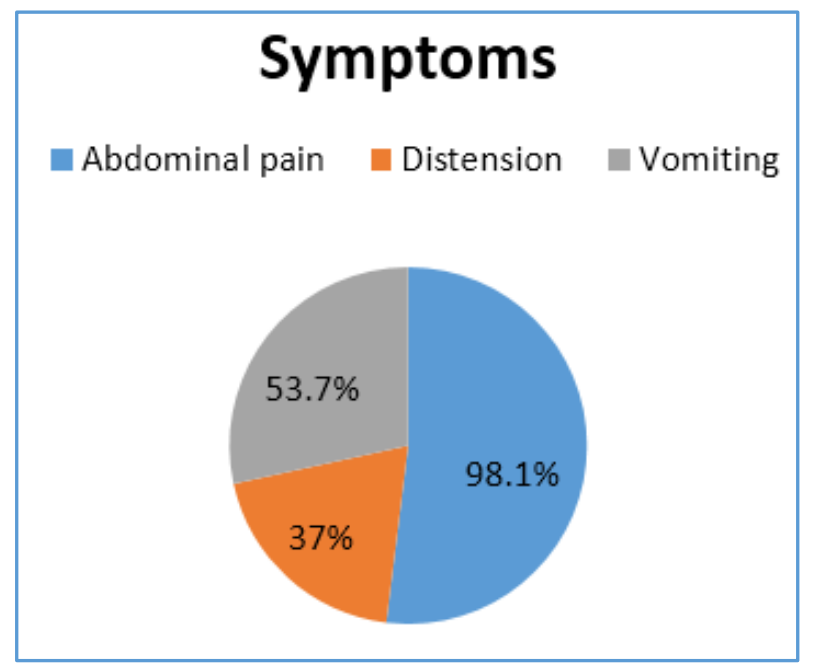

Graph 1

\section{Aetiology}

\begin{tabular}{|c|c|c|}
\hline Aetiology & No. of Patients & Percentage (\%) \\
\hline Alcohol & 52 & $\mathbf{9 6 . 3 \%}$ \\
\hline Idiopathic & 2 & $3.7 \%$ \\
\hline \multicolumn{3}{|c|}{ Table 1 } \\
\hline
\end{tabular}

\section{Blood Investigations}

\section{Serum Amylase}

It is evident from this study that increased level of serum amylase is an essential feature of acute pancreatitis. But the pattern of the hyperamylasaemia is extremely variable and highly sensitive, but not specific. Pattern increase or decrease does not correspond with the severity, complications or treatment modality.

\begin{tabular}{|c|c|c|}
\hline Serum Amylase & No. of Patients & Percentage (\%) \\
\hline$<80$ & 3 & $5.6 \%$ \\
\hline $80-499$ & 36 & $66.7 \%$ \\
\hline $500-999$ & 7 & $13 \%$ \\
\hline$>1000$ & 8 & $14.8 \%$ \\
\hline \multicolumn{3}{|c|}{ Table 2 } \\
\hline
\end{tabular}

\section{Serum Lipase}

Serum lipase is only secreted by the pancreas and thus more specific. In acute pancreatitis, serum lipase level may be elevated more consistently and for longer half-life than serum amylase. $(5,6,7)$ In our study, it is seen elevated in all patients.

\begin{tabular}{|c|c|c|}
\hline Serum Lipase & No. of Patients & Percentage (\%) \\
\hline$<100$ & 12 & $22 \%$ \\
\hline $100-499$ & 23 & $42.6 \%$ \\
\hline $500-999$ & 15 & $27.8 \%$ \\
\hline$>1000$ & 4 & $7.4 \%$ \\
\hline \multicolumn{3}{|c|}{ Table 3 } \\
\hline
\end{tabular}

Biochemical tests were done in this study. Elevated TC was suggestive of the infection in the pancreas, but it was nonspecific. Altered renal function test in about 2 patients was due to systemic complications of Acute pancreatitis, which lead to shock and renal failure. S. bilirubin, SAP and SGPT were elevated in 8 cases of Acute pancreatitis due to biliary tract disease or due to pathology of the pancreas involving the head and periampullary region. In majority of patients, x-rays chest did not reveal any information about diagnosis. Raised hemidiaphragm may be seen due to either pancreatic or retropancreatic oedema or due to pseudocyst. Pleural effusion was present as the systemic complications of acute pancreatitis. In $26 \%$ of patients, paralytic ileus was present on $\mathrm{x}$-ray abdomen.

\section{Ultrasonography}

USG was performed as and when required in all the patients of this study. Thus, it is evident that almost all types of acute pancreatitis can be diagnosed by ultrasonography, as USG has high sensitivity.

\begin{tabular}{|c|c|c|}
\hline $\begin{array}{c}\text { USG } \\
\text { Findings }\end{array}$ & $\begin{array}{c}\text { No. of } \\
\text { Patients }\end{array}$ & $\begin{array}{c}\text { Percentage } \\
\text { (\%) }\end{array}$ \\
\hline Oedematous pancreas & 36 & $66.7 \%$ \\
\hline $\begin{array}{c}\text { Peripancreatic fluid } \\
\text { collection }\end{array}$ & 2 & $3.7 \%$ \\
\hline Pancreatic calcification & 2 & $3.7 \%$ \\
\hline Pseudocyst & 5 & $9.3 \%$ \\
\hline Ascites & 2 & $3.7 \%$ \\
\hline Pleural effusion & 3 & $5.6 \%$ \\
\hline Normal & 4 & $7.4 \%$ \\
\hline \multicolumn{2}{|c|}{ Table 4 } \\
\hline
\end{tabular}

\section{CECT Abdomen}

Though contrast enhanced computerised tomography (CECT) abdomen is most valuable tool for diagnosis of acute pancreatitis and grading of severity and its local complication. ${ }^{(8,9)}$ Out of 54 patients, all underwent CT abdomen and pelvis. The Balthazar scoring of these patients ranges from 1 to 10 . 


\section{Balthazar scoring}

Balthazar Grade

Balthazar Grade

- Grode A

Appecrance on Cl

Normal CT

- Grodie a

Focal $\alpha$ diffuse eniargement of the pancreas

- Crode C

Pancreatic gland abnormalites and peripancreafic inflammation

Fuid colloction in a singlo tocation

- Grode D

Two or more fluid colections and / or gas bubbles in or adjacent to pancreas

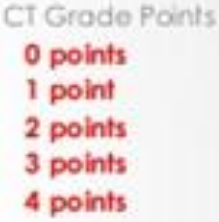

Necrosis score

Nocrosis Percentone

- No necrosís

- $01030 \%$ necrosis

- 30 to $50 \%$ nectosis

2 points

- Over $50 \%$ necrosis

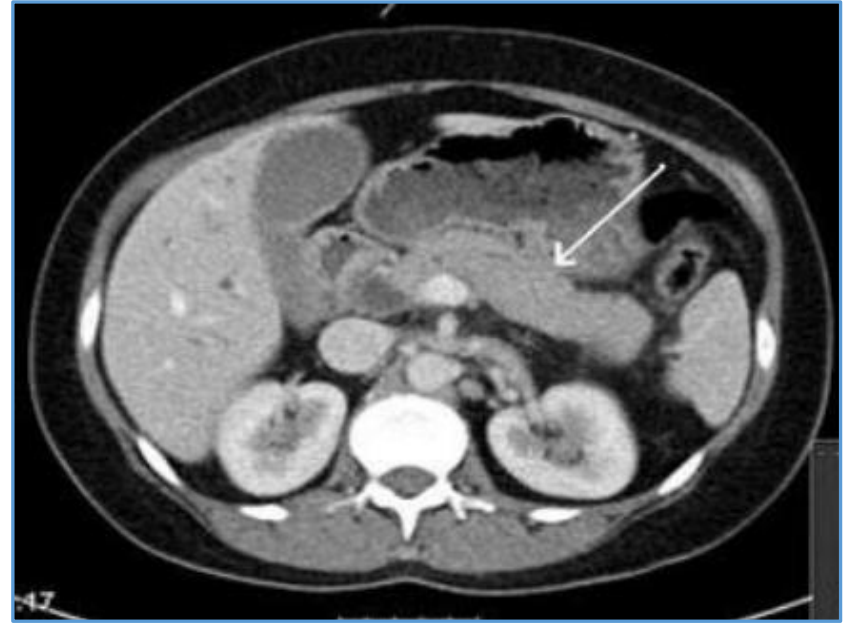

Figure 1. Grade 1-Mild Acute Pancreatitis

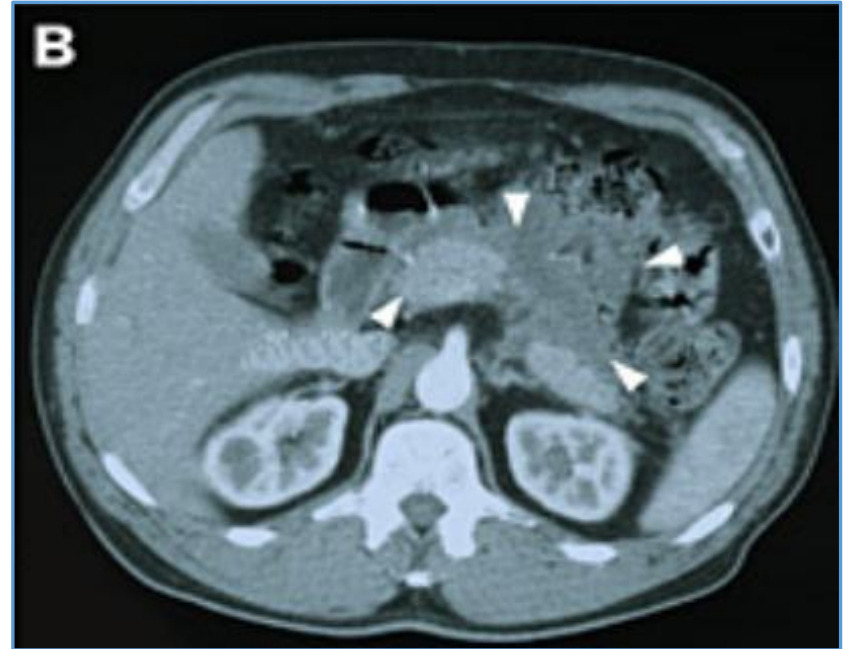

Figure 2. Grade 2-Moderate Acute Pancreatitis

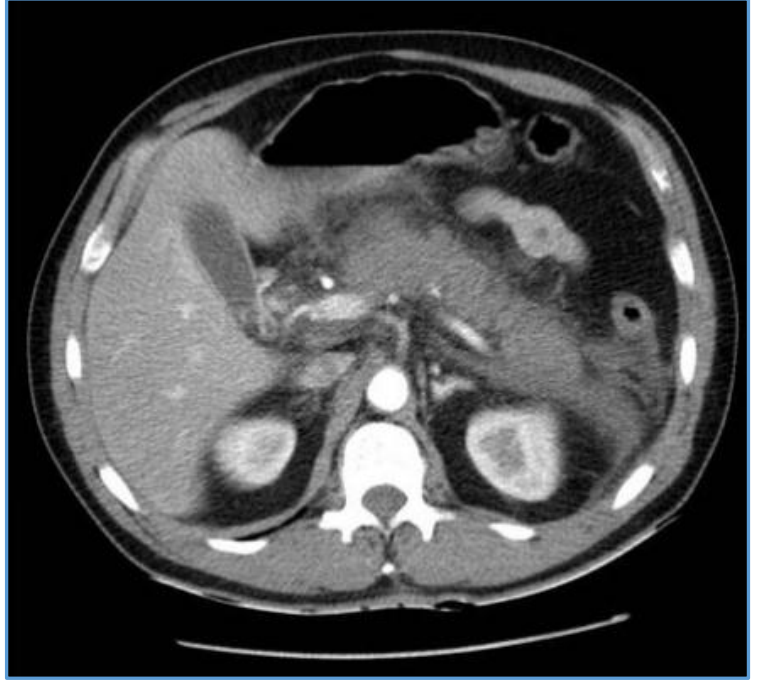

Figure 3. Grade 3- Severe Acute Pancreatitis

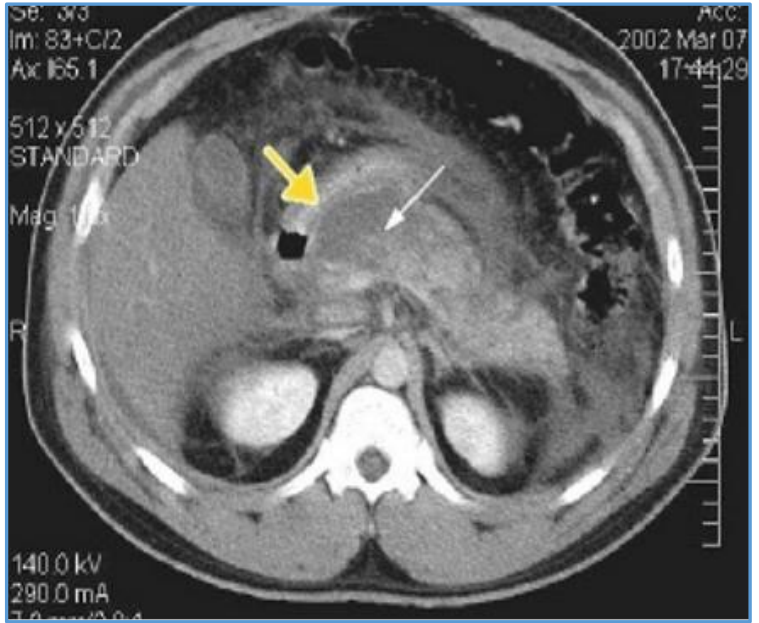

Figure 4. Grade 4- Necrotising Acute Pancreatitis 


\begin{tabular}{|c|c|c|}
\hline CT Grading & No. of Patients & Percentage (\%) \\
\hline GRADE 1 & 30 & $55.6 \%$ \\
\hline GRADE 2 & 14 & $25.9 \%$ \\
\hline GRADE 3 & 8 & $14.8 \%$ \\
\hline GRADE 4 & 1 & $1.9 \%$ \\
\hline \multicolumn{3}{|c|}{ Table 5 } \\
\hline
\end{tabular}

\section{Management}

The principles of conservative management followed in each case were adequate analgesia, correction of fluid and electrolytes imbalance, complete GI tract rest and Antibiotics.(10,11)

\begin{tabular}{|c|c|c|}
\hline Management & No. of Patients & Percentage \\
\hline Conservative & 53 & $98.1 \%$ \\
\hline Surgical & 1 & $1.9 \%$ \\
\hline Total & \multicolumn{2}{|c|}{$\mathbf{5 4}$} \\
\hline \multicolumn{3}{|c|}{ Table 6 } \\
\hline
\end{tabular}

Ryle's tube inserted in all patients was found to decrease vomiting, protect patients from aspiration and decompress the gut in ileus. Continuous radiological, biochemical and clinical monitoring was done in every case to prevent complications and for better prognosis of the patients. Most of the patients who had bowel sounds without any abdominal distension started enteral feeding 24 hours after admission without octreotide injection.(12,13,14)

\section{Complications}

During this study, total $18 \%$ of patients developed complication. Acute fluid collection- 4 patients, Pseudocyst- 5, patients with Pancreatic Calcifications- 8, Pleural Effusion- 2 and Necrotising Pancreatitis- 1.

\section{CONCLUSION}

The highest incidence of acute pancreatitis was found in the age group of 25 to 35 years followed by the age group of 35 to 45 years. It was relatively less common in the extremes of age groups. Acute pancreatitis was found more commonly in males compared to females. This may be due to effect of alcohol addiction in males due to alcoholism. Acute pancreatitis usually presents with abdominal pain, nausea, vomiting, fever, jaundice and abdominal distention and physical examination reveals epigastric tenderness, guarding, rigidity, pyrexia and shock mostly. Most of acute pancreatitis were of the mild type. The most common systemic complications were pulmonary, followed by renal complications like ARF. DIC was found in one patient. The most common local complications were acute fluid collection and pseudopancreatic cyst. Pancreatic necrosis, pancreatic abscess were found only in patients having severe pancreatitis. Serum amylase and serum lipase are the best biochemical indicators of the disease, supplemented by serial ultrasound examinations of the abdomen. The prognostic factors for this disease are hyperamylasaemia, hyperglycaemia reflecting a poorer outlook. Prognosis can also be assessed by ultrasonography and computed tomography delineating local complications. USG abdomen is a good, readily available, non-invasive mean to detect local pathology, which may be readily repeated. CECT abdomen is sensitive and specific detecting the severity and grading of acute pancreatitis based on Balthazar CT Scoring System. Peripancreatic fluid collection and pancreatic necrosis are predictors of severity of pancreatitis on USG and CT scan findings. So, serum amylase level more than three-fold of normal level and pancreatic fluid collection is main predictor of severity of pancreatitis in our study. About $99 \%$ of patients were treated conservatively. Octreotide was not used in our study. The initial management of AP should be conservative with surgery reserved for case having uncertainty of diagnosis, very severe type not responding to medical therapy and complications of disease. Surgical management was done in $1 \%$ of patients.

\section{REFERENCES}

[1] Kandasami P, Harunarashid H, Kaur H. Acute pancreatitis in multi-ethnic population. Singapore Med Journal 2002;43(6):284-8.

[2] Surati K, Suthar K, Shah J, et al. Study of recent trends in acute pancreatitis. International Journal of Medical Science and Public Health 2014;3(1)63-8.

[3] Whitcomb DC. Clinical practice. Acute pancreatitis. N Eng J Med 2006;354(20):2142-50.

[4] Beger HG, Rau BM. Severe acute pancreatitis: clinical course and management. World J Gastroenterology 2007;13(38):5043-51.

[5] Elfar M, Gaber LW, Sabek 0, et al. The Inflammatory cascade in acute pancreatitis: relevance to clinical disease. Surg Clin North Am 2007;87(6):1325-40.

[6] Larson SD, Nealon WH, Evers BM. Management of gallstone pancreatitis. Adv Surg 2006;40:265-84.

[7] Banks PA, Freeman ML. Practice guidelines in acute pancreatitis. Am J Gastroenterology 2006; 101(10): 2379-400.

[8] Lynch M, HMS III, Lieberman G. Multi-modality imaging in acute pancreatitis. MDBIDMC Core Clerkship in Radiology 2009.

[9] Balthazar EJ, Robinson DL, Megibow AJ, et al. Acute pancreatitis: value of CT in establishing prognosis. Radiology 1990;174(2):331-6.

[10] Working Party of the British Society of Gastroenterology, Association of Surgeons of Great Britain and Ireland, Pancreatic Society of Great Britain and Ireland, et al. UK guidelines for the management of acute pancreatitis. Gut 2005;54(Suppl 3):iii1-9.

[11] Mao EQ, Tag YQ, Fej J, et al. Fluid therapy for severe acute pancreatitis in acute response stage. Chin Med J (Engl) 2009;122(2):169-73.

[12] Petrov MS, Loveday BPT, Pylychuk RD, et al. Systematic review and meta-analysis or enteral nutrition formulations in acute pancreatitis. $\mathrm{Br} \mathrm{J}$ Surgery 2009;96(11):1243-52. 
[13] De Vries AC, Besselink MGH, Van der Kraats CIB, et al. Antibiotic prophylaxis in acute necrotizing pancreatitis: methodological, quality of randomised controlled trials in relation to outcome. Gut 2005;54(Suppl 7):A38-A9.
[14] Wittau M, Mayer B, Scheele J, et al. Systematic review and meta-analysis of antibiotic prophylaxis in severe in acute pancreatitis. Scand J Gastroenterology 2011;46(3):261-70. 